\section{3}

BNWL - 1850 PT 4 UC- 48 , Biomedical and Environmental Research

PACIFIC NORTHWEST LABORATORY

ANNUAL REPORT FOR 1973

to the

USAEC Division of Biomedical and Environmental Research

Part 4 Physical and Analytical Sciences

by

J. M. Nielsen

with Major Contributions from

Staff Members of

Radiological Sciences Department

Physics and Instrumentation Department

February 1974

BATTELLE

PACIFIC NORTHWEST LABORATORIES

RICHLAND, WASHINGTON 99352 
NUCLEAR MEDICINE TECHNOLOGY

AND OTHER HEALTH APPLICATIONS

- NUCLEAR POWERED PROSTHESES

- MEDICAL USES OF ISOTOPES 


\title{
- NUCLEAR POWERED PROSTHESES
}

\begin{abstract}
A 50-watt intrathoracic ${ }^{238} \mathrm{Pu}^{16} \mathrm{O}_{2}$ heat source in a miniature swine produced no clinical signs of untoward effect over a period of almost 10 months, in spite of aortic occlusion and burnup some time prior to sacrifice. Retroperitoneal abdominal implant experiments indicate surface heat flux tolerance limits of less than 0.01 watts $/ \mathrm{cm}^{2}$ immediately postoperatively, increasing to nearly 0.04 watts/cm ${ }^{2}$ within one month, exploiting surface tissue ingrowth techniques. A miniature swine continues on experiment with a 29-watt $238 \mathrm{Pu}^{16} \mathrm{O}_{2}$ heat source implanted retroperitoneally in a discoid aluminum container with a velour fabric coat.
\end{abstract}

Biological Effects of Intracorporea1 Radioisotope Heat Sources

M. F. Gillis, J. R. Decker,

J. M. Creer, R. D. Carmichael,

N. R. Gordon, F. T. Cross,

L. G. Smith and J. L. Beamer

The objectives of this program are to study in miniature swine the short- and long-term effects of heat and radiation from intracorporeal radioisotope heat sources similar to those envisioned for use in totally implanted cardiac assist/replacement systems and to obtain basic information on bulk tissue heat conductivity in the vicinity of large, tissueingrown radioactive implants as required to establish engineering design criteria for prototype systems.

Intrathoracic (intraaortic) and abdominal (retroperitoneal) heat exchangers with electrical (for surface temperature versus heat flux studies) and encapsulated ${ }^{238} \mathrm{Pu}^{16} \mathrm{O}_{2}$ heat sources (29- and 50-watt), the latter for long-term study of biological effects of their heat and radiation, are implanted in female miniaturc swine having a body mass similar to an adult man. We will implant smaller, planar devices in various locations to obtain basic information on tissue heat conductivity and its variation with type of tissue and with time following implantation, using heat generating surfaces which encourage tissue ingrowth.

A thermally insulated, Silastic coated graphite heat exchanger containing a 50 -watt ${ }^{238} \mathrm{Pu}^{16} \mathrm{O}_{2}$ heat source was implanted in the descending thoracic aorta of a female miniature swine on February 8, 1973, using aortic blood flowing through the device as a coolant. Except for a few days of lethargy and anorexia in September, we noted no evidence (physical examination, periodic hematology, serum chemistry and sternal marrow biopsy) of untoward sequelae until 1 ate November. On November 27 anorexia, lethargy, mild dyspnea, relative neutrophilia and elevated lactic acid dehydrogenase prompted radiographic examination (Figure 3.1) 


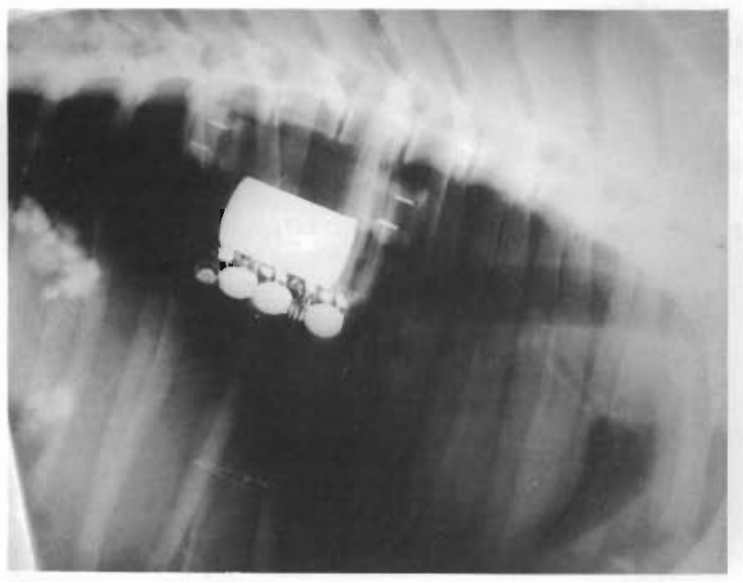

(a)

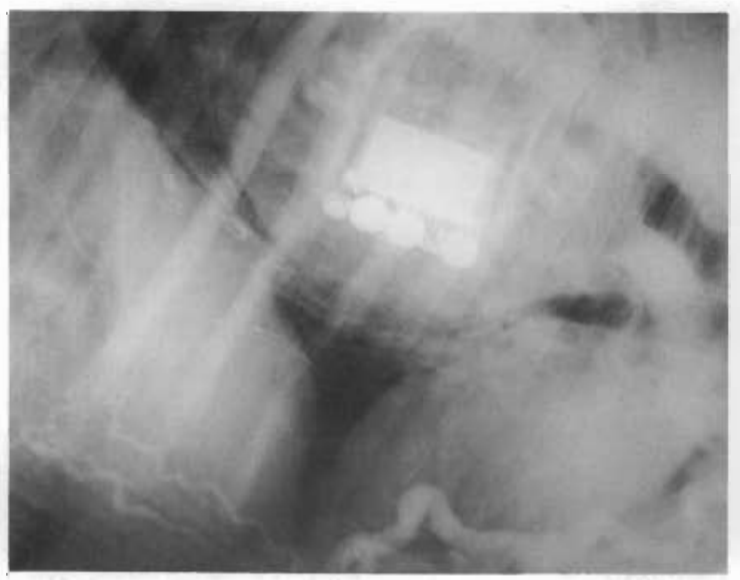

(c)

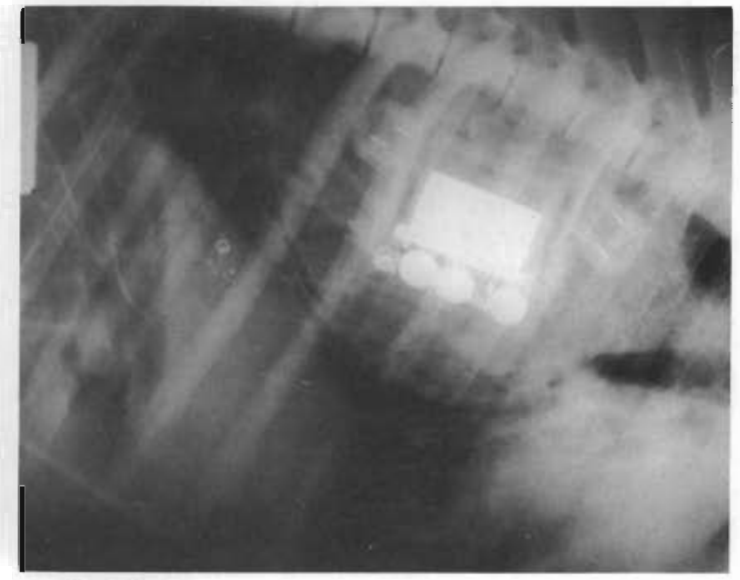

(b)

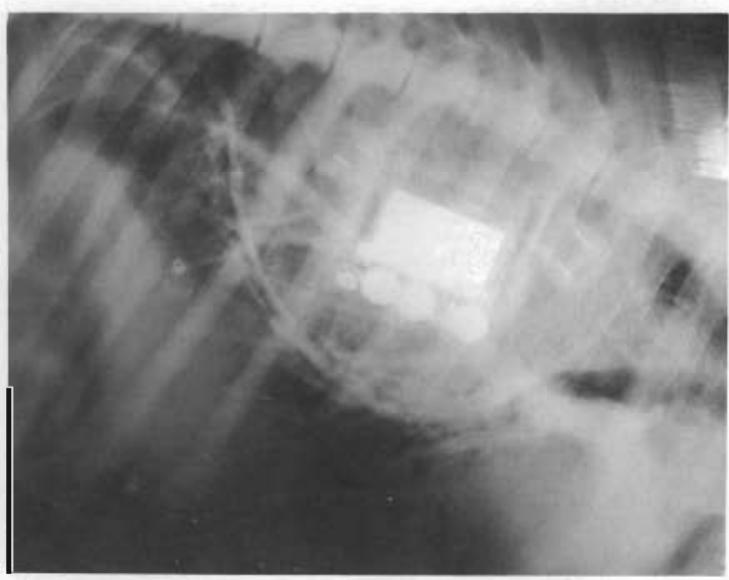

(d)

FIGURE 3.1. Lateral Radiograms of Animal No. 4442 Following Implantation of an Intrathoracic Aortic Heat Exchanger Containing a 50-watt Plutonium-238 Heat Source. (a) Immediately following implantation, (b,c,d) ca. 42 weeks after implantation. (b) Flat film revealing large, dense scar tissue capsule surrounding implant; (c) aortogram showing total occlusion of aorta anterior to the implant, hypertrophied collateral arterial circulation (especially the internal thoracic arteries) and dense matrix of arteries in the scar tissue capsule; (d) pulmonary arteriogram showing its considerable contribution to the arterial supply in the scar tissue capsule. 
which confirmed device occlusion. Except for the obliteration of a portion of the thoracic aorta, the presence of a large and thick vascular scar tissue capsule (with a charred lining), and cooked (1iterally) vertebral bodies and intervertebral discs over the implant site, there were no remarkable gross necropsy findings. Numerous special and routine tissue specimens are now in the process of histopathological evaluation. Three control animals (same implant but a lead slug in place of the heat source) continue on experiment without incident.

Spherical ( 5 in. diam) and discoidal (8-in.-diam x 3-in.-center thickness) implants containing electrical heaters and internal and surface thermistors were implanted retroperitoneally in the ventrolateral abdomen of miniature swine. We first established that surface heat fluxes, reported elsewhere as tolerable, (1) parboils tissues and produces death within a few days under such conditions. We estimate that, immediately following implantation of such massive implants, local surgical shock and anatomic discuption limit tolerable surface heat flux to something less than 0.01 watts $/ \mathrm{cm}^{2}$. We also established, however, that surface heat flux tolerance increases marked$1 y$ with time due to restoration of normal local blood perfusion and surface ingrowth of vascularized scar tissue.

On December 6, 1973, three weeks following implantation, we surgically removed the electrical heater from a discoidal implant and replaced it with a 29 -watt ${ }^{238} \mathrm{Pu}^{16} \mathrm{O}_{2}$ heat source. This produces a surface heat flux of 0.036 watts $/ \mathrm{cm}^{2}$ and an interface temperature of $108^{\circ} \mathrm{F}$ or less (Figure 3.2). Based on the preceding three weeks of experimentation with electrical heating and favorable observations at surgery, this animal should continue on experiment indefinitely.

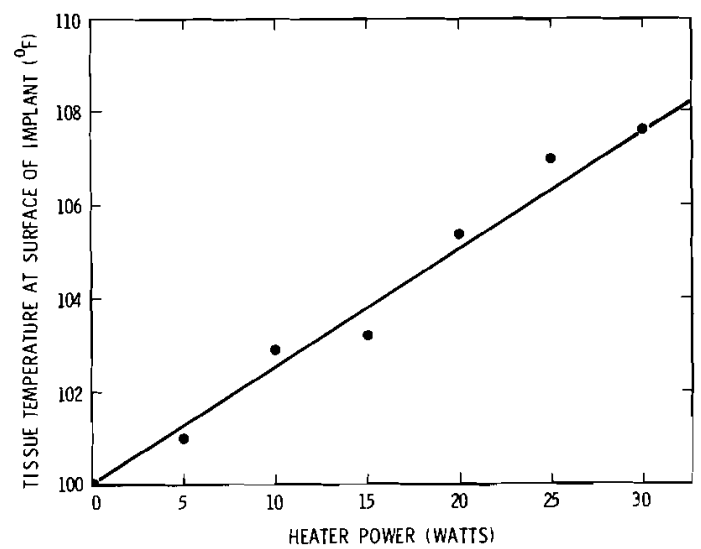

FIGURE 3.2. Tissue Temperature $\left({ }^{\circ} \mathrm{F}\right)$ at the Surface of a Velour Covered Retroperitoneal Discoid Implant Versus Applied Internal Heater Power (watts) Three Weeks Following Implantation Surgery; surface heat flux $=($ power $/ 810)$ watts $/ \mathrm{cm}^{2}$ 
Estimates of the surface area represented by the viable tissue shell

of the scar capsule enclosing the thoracic source (not tissue-ingrown) suggest that, given adequate time for proper capsule development and vascularization, surface heat fluxes of up to 0.06 watts $/ \mathrm{cm}^{2}$ or more may be eventually tolerable. Abdominal experiments, however, suggest a practical tolerance 1 imit (after 3 weeks of healing, exploiting surface ingrowth of tissue) of about half that. The low tolerance limit immediately after source implantation (less than 0.01 watts $/ \mathrm{cm}^{2}$ ) means that existing subsystem prototypes may have to be cooled temporarily by means other than direct conduction during the postoperative healing period. 


\title{
- MEDICAL USES OF ISOTOPES
}

\author{
An inexpensive portable blood irradiator for clinical use \\ in suppressing circulating lymphocytes and organ graft rejec- \\ tion and a generator for Nitrogen-13 ( $\left.T_{1 / 2}=10 \mathrm{~min}\right)$ suitable \\ for clinical diagnosis are two applications for isotopes \\ being investigated under this program. \\ A new approach to blood irradiation has been developed \\ using Thulium-170 cast as an integral part of a vitreous car- \\ bon body. Production of the irradiators does not involve \\ personnel exposures since the $169 \mathrm{Tm}$ used is neutron activated \\ after manufacture. Reactivation is anticipated as units lose \\ effectiveness with the 125-day half-life of $170 \mathrm{Tm}$. Total \\ weight of units applicable to clinical practice is anticipated \\ to be less than $1 \mathrm{~kg}$. An irradiator using stronium-90- \\ yttrium-90 was also constructed and tested in a dog. \\ Alpha irradiation of Boron-10 is the basis route being in- \\ vestigated for the $13 \mathrm{~N}$ hospital generator. Both $13 \mathrm{~N}_{2}$ and \\ ${ }^{1} \mathrm{NH}_{3}$ have potential value as diagnostic pharmaceuticals. \\ Nitrogen-13 has been produced in proof-of-principle tests \\ using the $10_{B(\alpha, n)} 13 N$ reaction with Americium-241 as the al- \\ pha source. Significant quantities of ${ }^{13} \mathrm{~N}$ were measured in \\ the $B$ powder and trace quantities of ${ }^{13} \mathrm{~N}$ were detected in a \\ sweep gas. Use of $B N$ is expected to release more gaseous \\ products. Methods are currentzy under study for producing \\ ${ }_{13} \mathrm{NH}_{3}$, principal among these is the use of $\mathrm{KOH}$ to release \\ $1^{13} \mathrm{H}$ from irradiated powder. primary criteria are cost, \\ simplicity and short process time.
}

Development of a Blood Irradiator

F. P. Hungate, D. H. Lester,

W. F. Riemath, L. R. Bunne11,

M. F. Gillis and N. Robinson

Blood irradiation to suppress tissue and organ rejection and to control some blood diseases has been shown to be successful. It has also been demonstrated that chronic irradiation may be superior to repetitive acute exposures. This work is $\mathrm{di}$ rected toward developing small inexpensive irradiators for clinical use and evaluating their effectiveness in animals for suppressing the cellular immune reaction under different dose rate regimes. ${ }^{90} \mathrm{Sr}{ }^{90} \mathrm{Y}$ irradiators, reported in the literature, have linearized the source material and thus have required distributed and relatively heavy shielding. To minimize the shielding, we contained $2 \mathrm{Ci}$ of ${ }^{90} \mathrm{Sr}^{90} \mathrm{Y}$ in a cylindrical zone $1 \mathrm{~cm}$ long within an approximately $25-\mathrm{mm}$ thick outer layer of Hevimet shielding. A $0.025-\mathrm{mm}-\mathrm{thick}$ layer of titanium covered the ${ }^{90} \mathrm{Sr}^{90} \mathrm{Y}$; see Figure 3.3. Thin-walled Silastic tubing, $2.64 \mathrm{~mm} \mathrm{ID}$ and $3.66 \mathrm{~mm} \mathrm{OD}$, served to transport the circulating 


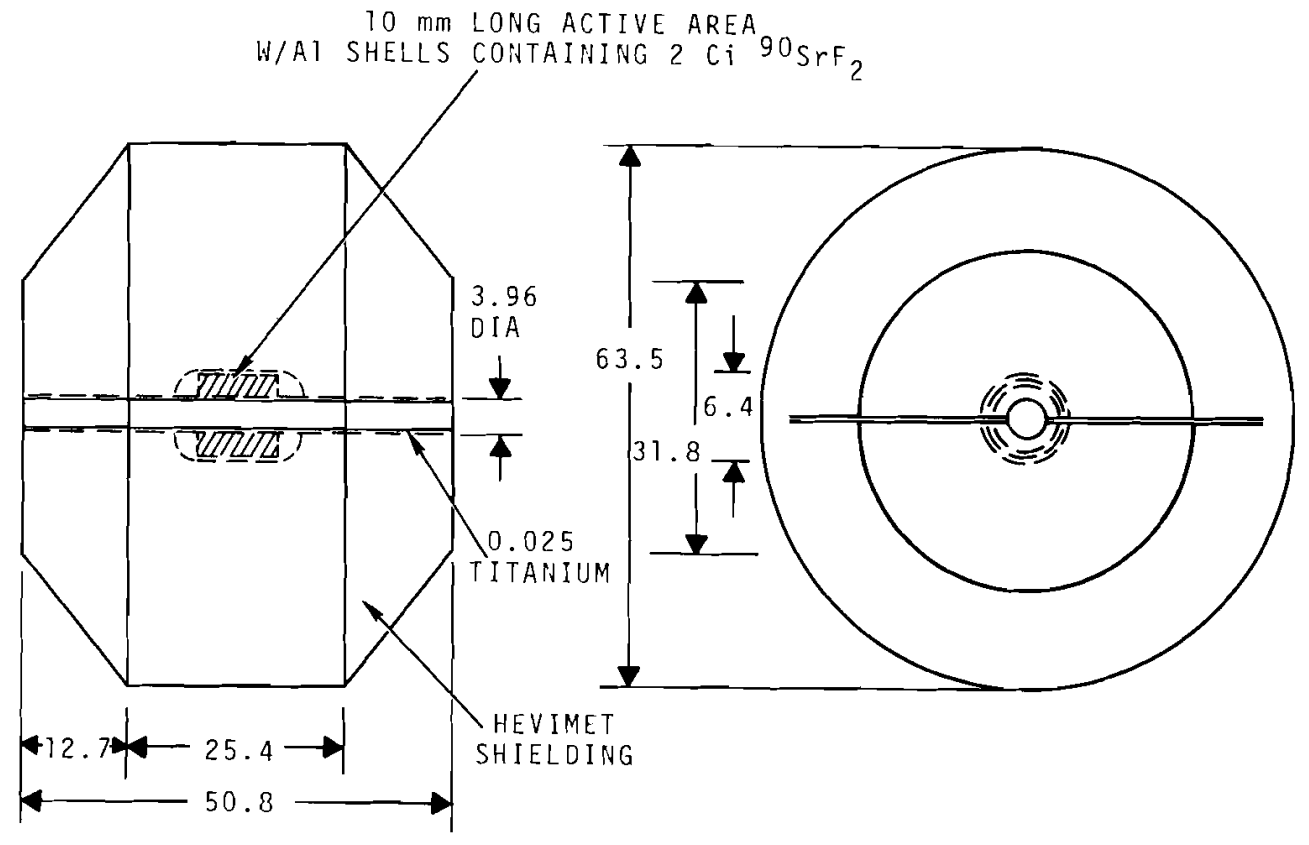

FIGURE 3.3. Schematic of the Mark XIV

${ }^{90} \mathrm{Sr}^{90 Y}$ Irradiator (units in millimeters)

blood through the irradiator. The blood dose was estimated by passing Fricke dosimeter solution through the Silastic tubing at known flow rates and measuring optical density change. The transit dose to blood was estimated to be 40 rad at a flow rate of $100 \mathrm{ml} / \mathrm{min}$. Total weight of the irradiator (Figure 3.4) was slightly less than $2 \mathrm{~kg}$. When the arteriovenous shunt was installed in the dog, the blood flowed through the irradiator more than $8 \mathrm{hr}$ but less than $12 \mathrm{hr}$ before clotting occurred and the shunt was removed. Following this dose of 2000 to $3000 \mathrm{rad}$, the levels of small lymphocytes fell and remained at approximately $2 / 3$ of their pre-exposure level for 6 weeks, well after other blood constituents had returned to pre-implant levels.

Embrittlement of the Silastic tube was observed which stimulated the consideration of alternative materials for the blood interface and body of the irradiator. Carbon is little affected by radiation, even at intensities in the core of reactors. As pyrolytic graphite, it is also essentially nonthrombogenic. It is a low 2 material and produces minimum bremsstrahlung. We selected a recently developed technique of polymerizing polyfurfuryl alcohol with subsequent vacuum high temperature carbonizing that produces a vitreous carbon. This casting technique also permits inclusion of the source material as an integral part of the carbon body. Thulium-170 was chosen to be the radiation source because of its 125-day half-life and its maximum energy beta of $0.96 \mathrm{MeV}$. A11 the carbon casting can be done with nonradioactive ${ }^{169} \mathrm{Tm}$ and neutron activation of the encapsulated ${ }^{169} \mathrm{Tm}$ to 


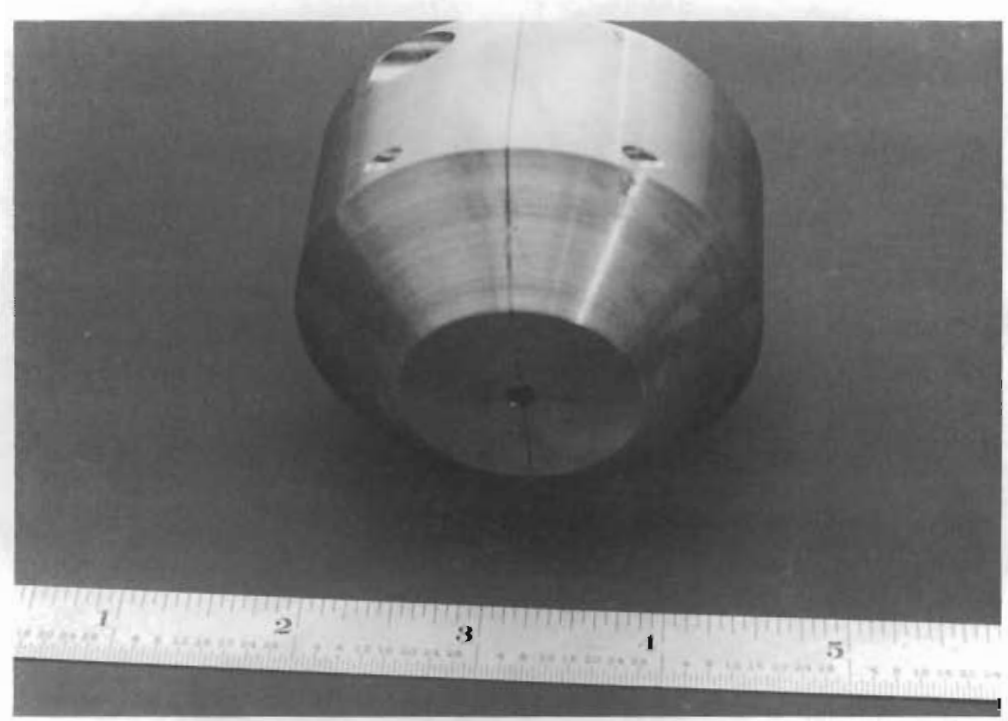

\section{Neg $731930-2 \mathrm{CN}$}

FIGURE 3.4. Photograph of the Mark XIV Irradiator Ready For Insertion of the Silastic Blood Transport Tube

form ${ }^{170} \mathrm{Tm}$. Furthermore, the unit can be repeatedly reactivated as its effective strength declines below useful levels. Figure 3.5 is a section through the wall of the vitreous carbon showing the $0.05-\mathrm{mm}$ inner barrier of carbon, the $0.15-\mathrm{mm}$ layer of ${ }^{169} \mathrm{Tm}_{2} \mathrm{O}_{3}$ and the $2.3-\mathrm{mm}$ covering 1 ayer of carbon. Note the micro as well as macro containment of the source material. Total weight of the vitreous carbon unit following carbonizing is $2 \mathrm{~g}$; with a containment layer of $6.4 \mathrm{~mm}$ of lead, the weight is $160 \mathrm{~g}$. Figure 3.6 illustrates the components of the first prototype and Figure 3.7 shows them assembled.

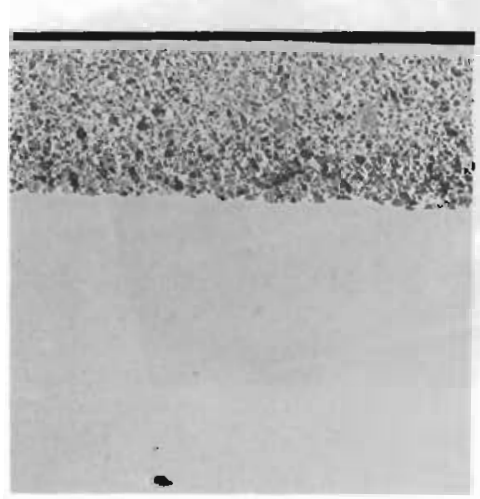

INNER SURFACE

- VITREOUS CARBON CONTAINMENT LAYER $(0.05 \mathrm{~mm})$

- -VITREOUS CARBON CONTAINING Tm${ }_{2} 0_{3}(0.15 \mathrm{~mm})$

- vitreous carbon

OUTER LAYER $2.3 \mathrm{~mm}$ THICK

FIGURE 3.5. Longitudinal Section Through the Wall of the Vitreous Body of the Thulium Irradiator (X180) 


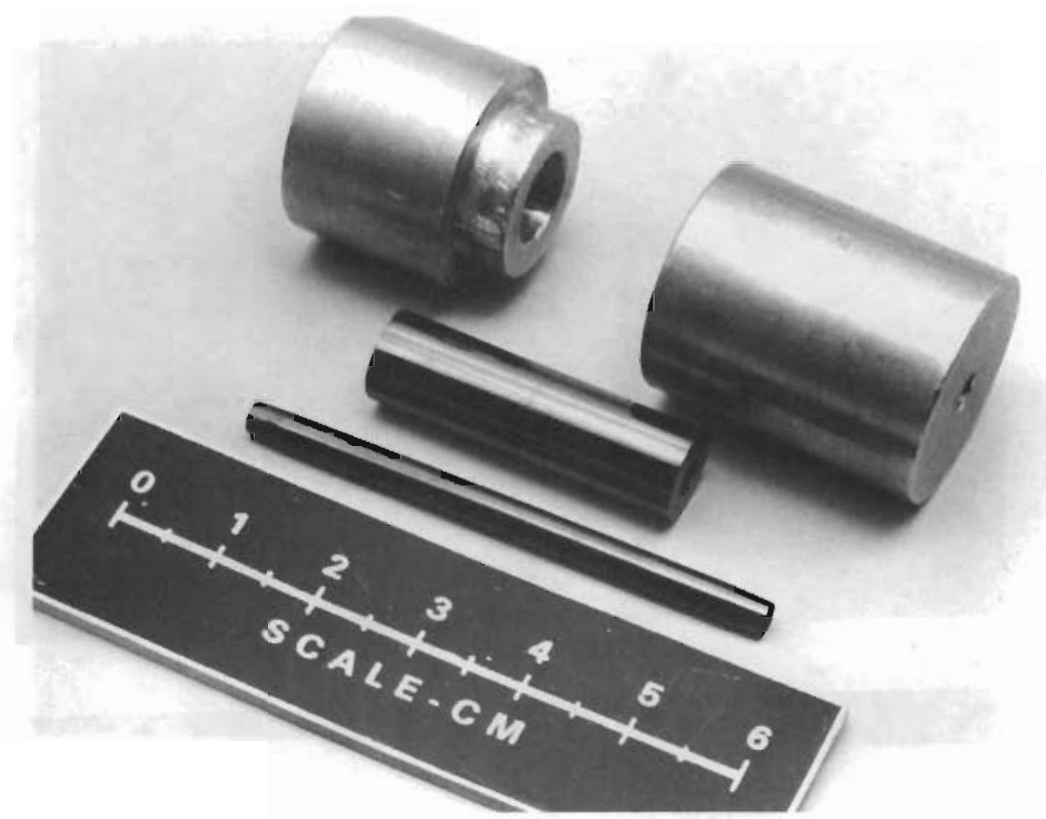

Neg $735804-4 \mathrm{CN}$

FIGURE 3.6. Prototype Thulium Irradiator Components: the Pyrolytic Graphite Blood Tube, $2.8 \mathrm{~mm}$ ID, $3.3 \mathrm{~mm}$ $O D$, and $51 \mathrm{~mm}$ long, the 2-gram Vitreous Carbon Irradiator Body, and the Lead Shield

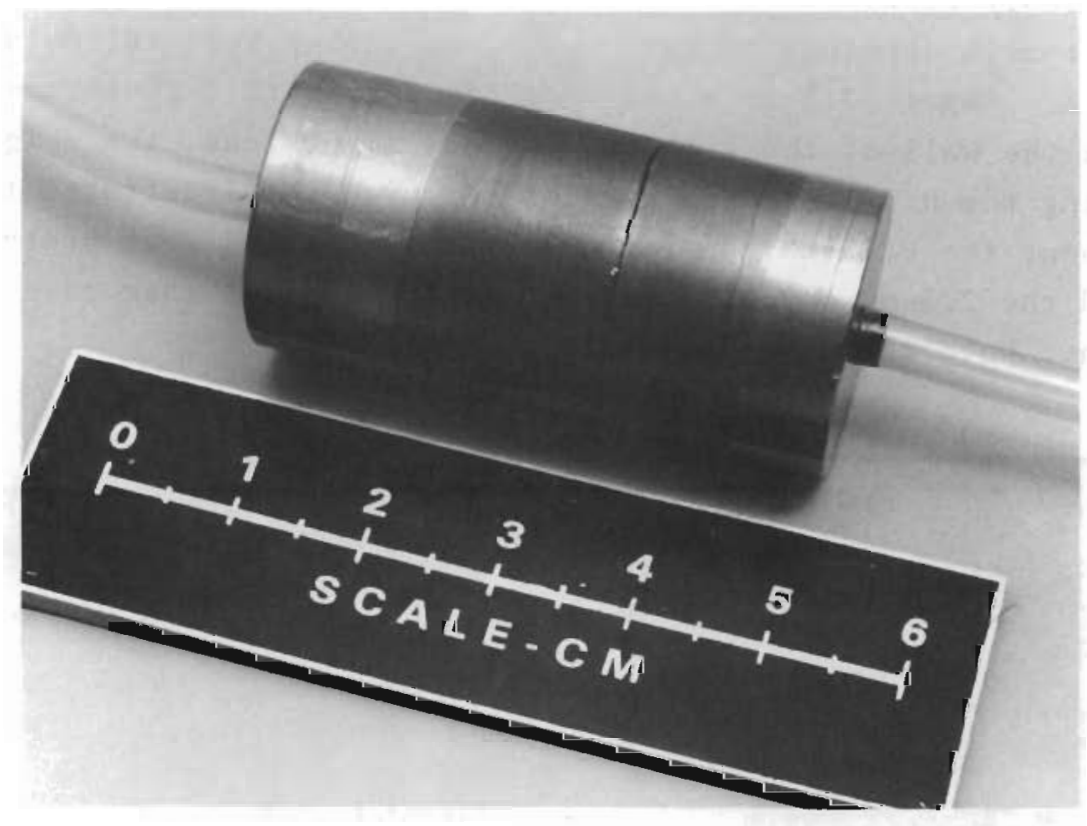

Neg $735804-3 \mathrm{CN}$

FIGURE 3.7. Prototype Thulium Irradiator Assembled with Silastic Tubing to Connect to Shunt Cannulas; Total wt $160 \mathrm{~g}$ 
In this initial ${ }^{170}$ Tm irradiator, a pyrolytic graphite tube ${ }^{(2)}$ having a $0.025-\mathrm{mm}$ wall thickness is used as the blood interface because of its non-thrombogenic character. Silastic tubing connects this graphite tube to the arterial and venous cannulas. External dose rates were less than $50 \mathrm{mR} / \mathrm{hr}$ at the surface and a transit dose of $21 \mathrm{rad}$ (at a flow rate of $100 \mathrm{~m} 1 / \mathrm{min}$ ) was measured by Fricke dosimetry. This unit is being tested on a miniature goat for effectiveness in suppressing lymphocyte levels and extending skin allograft rejection times.

Calculations using the Unidentified Flowing objects (UFO) code (3) indicate the possibility of obtaining several-fold higher transit doses if the vitreous carbon can serve as the blood interface. Figure 3.8 shows the dose profile calculated for a

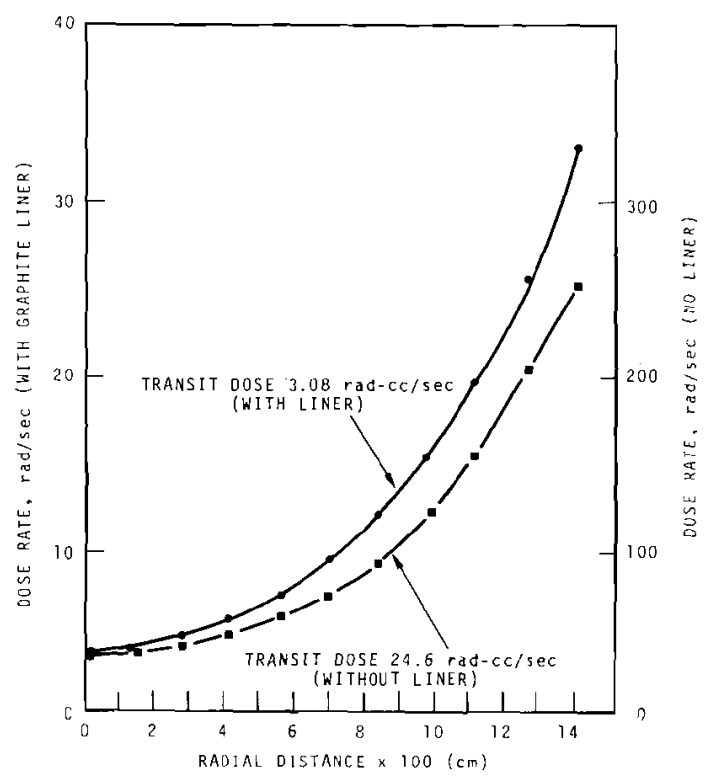

FIGURE 3.8. Calculated Cross-Section Dose Rates to Blood from a $1-\mathrm{Ci}$ $170 \mathrm{Tm}$ Source typical unit and for a comparable unit without a liner. Samples of vitreous carbon are now being tested for their thrombogenicity but no data are yet available.

The combined use of ${ }^{170} \mathrm{Tm}$ and vitreous carbon offers excellent potential for developing inexpensive, safe and lightweight blood irradiators for testing and for appropriate clinical application. Until the development of this irradiator, testing for effects from chronic irradiation had not been possible; now broader use can be expected. The greatest initial use is expected to be in suppressing early rejection of kidney transplants. Also some forms of leukemia are reported to respond favorably to blood irradiation. Radiation safety during production and use of the units appears to be very favorable.

\section{Hospital Generator for Nitrogen-13}

D. H. Lester, W. F. Riemath and

J. A, Partridge

Nitrogen-13 is a positron emitter with a half-life of $10 \mathrm{~min}$. Tagged $\mathrm{N}_{2}$ gas provides a good diagnostic tool for lung function because the shortness of its half-life and low absorption in the lungs lead to a low body burden. ${ }^{13} \mathrm{~N}$ has been used successfully as a tracer to locate and size myocardial infarctions in experimental animals in the form of $13 \mathrm{NH}_{4}{ }^{+}$in solution and to detect tumors in animals. (4) Studies of 
kidney and liver function have also been suggested for ${ }^{13} \mathrm{NH}_{3}$ or ${ }^{13} \mathrm{NH}_{4}{ }^{+}$ solutions. Many other diagnostic uses are also possible because of the basic role of $\mathrm{NH}_{3}$ in body function.

The disadvantage of the use of ${ }^{13} \mathrm{~N}$ is that it must be generated at the time and place of its use. To date experimenters have used high-energy accelerators available at the site where the biological testing was performed. The most popular route is deuteron bombardment of methane, ${ }^{12} \mathrm{C}(\mathrm{d}, \mathrm{n}){ }^{13} \mathrm{~N}$. This reaction requires 8 to $10 \mathrm{MeV}$ deuterons which must come from an accelerator. Since the deuteron reaction requires special techniques, staff and equipment, widespread use is not practical. An effective ${ }^{13} \mathrm{~N}$ generator must be economical, easy to operate, safe to use, and readily accessible.

Early in the program a number of candidate reactions were screened for possible use. To date, the most promising is ${ }^{10} \mathrm{~B}(\alpha, \mathrm{n})^{13} \mathrm{~N}$. The boron may be used in a pure form or in a compound. Whatever process is used, the time from irradiation to output must be short due to the isotope's short half-life.

Proof-of-principle tests have been performed. The generation system consisted of a high-intensity ${ }^{241} \mathrm{Am}$ source of alpha particles adjacent to ${ }^{10} \mathrm{~B}$ in a container separated from the alpha source by Mylar film. This geometry was found necessary to eliminate background interference during counting to test for the presence of ${ }^{13} \mathrm{~N}$. The ${ }^{13} \mathrm{~N}$ production was verified by gamma-ray spectrometric measurements made on the assembly containing the ${ }^{10} \mathrm{~B}$. Counting peaks were observed in the energy channels appropriate for the annihilation gammas formed by positron decay of the ${ }^{13} \mathrm{~N}$. Peak height decay rates were in good agreement with the reported 10-min half-life of ${ }^{13} \mathrm{~N}$.

Supplementary experiments were conducted to determine the extent of ${ }^{13} \mathrm{~N}$ release from the ${ }^{10} \mathrm{~B}$ powder. Similar irradiation geometry was used for a smaller chamber containing ${ }^{10} \mathrm{~B}$. This chamber was connected, as shown in Figure 3.9, to a circuit which allowed the atmosphere of the ${ }^{10_{B}}$ chamber to be swept out, passed through two filters in series (each capable of removing particles $3 \mathrm{mi}-$ crons or larger in size), and counted in an external, separate chamber. In two experiments of this type, 13 and 18 counts of ${ }^{13} \mathrm{~N}$ were recorded for a 5-min counting period. In comparison, approximately 170,000 counts of ${ }^{13} \mathrm{~N}$ were recorded for a 5-min counting period in the first experiments in which the entire ${ }^{10} \mathrm{~B}$ assembly was counted.

These results indicate that for these approximate STP conditions, most of the ${ }^{13} \mathrm{~N}$ formed was retained in the ${ }^{10} \mathrm{~B}$. Preliminary indications

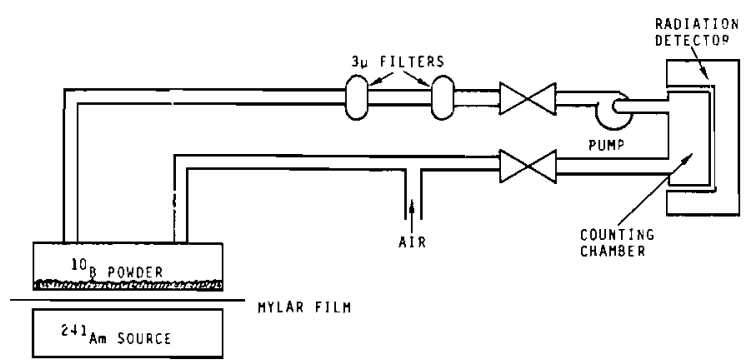

FIGURE 3.9. Schematic Diagram of Apparatus Used to Test $13_{\mathrm{N}}$ Release 
from thermodynamic calculations are that boron nitride formation is in fact favored in these circumstances. Thus, it appears that a practical $13 \mathrm{~N}$ generator design will require conditions more favorable for ${ }^{13} \mathrm{~N}$ release. Work is underway to explore use of $10 \mathrm{BN}$ powder to promote ${ }^{13} \mathrm{~N}$ release as a constituent of ${ }^{13} \mathrm{~N}^{14} \mathrm{~N}$ molecules. Boron nitride can be heated to high temperatures to aid nitrogen release. A1so under investigation are methods to produce ${ }^{13} \mathrm{NH}_{3}$. One direct route is alpha irradiation of ${ }^{10} \mathrm{BN}$ followed by treatment with KOH which will liberate $\mathrm{NH}_{3}$ gas, some of which is tagged with $13_{N}$. Early identification of the existence of ${ }^{13} \mathrm{~N}$ was made using such a method. (5) Another possibility is

$\mathrm{Mg}^{10} \mathrm{~B} \stackrel{\mathrm{rad} .}{\longrightarrow} \mathrm{Mg}^{13} \mathrm{~N}$ $\mathrm{Mg}^{13} \mathrm{~N} \stackrel{\text { moist air }}{\longrightarrow} \mathrm{MgO}+{ }^{13} \mathrm{NH}_{3}{ }^{\uparrow}$.
One advantage of this route is that $\mathrm{NH}_{3}$ should be the on $1 y$ gaseous product. The ammonia could be recovered in a bubbler (as is done in the ${ }^{12} \mathrm{C}(\mathrm{d}, \mathrm{n}){ }^{13} \mathrm{~N}$ route) and used as a ${ }^{+} \mathrm{NH}_{4}$ solution. It could also be possible to obtain $13_{\mathrm{N}}$ gas by treating the $\mathrm{NH}_{3}$ to liberate $\mathrm{N}_{2}$.

other boride compounds have been studied as possible candidates but many are unstable and too hazardous for use.

In addition to technical evaluations, economic evaluations are needed. At present, the quantity of $241_{\text {Am }}$ required is cost prohibitive. Studies are underway to determine how the cost of alpha irradiation can be reduced. 


\section{REFERENCES}

1. H. Rawson, "Studies of the Effects of Additional Endogenous Heat," Art. Heart Program Conf. Proc., June 9-13, 1969, Washington, D.C., R. J. Hegyeli, ed., Superintendent of Documents, U.S. Printing Office, p. 893 , 1969 .

2. Pyrolytic graphite tube obtained from Gulf Energy Environmental Systems of San Diego.

3. The local code was adapted and derived from the Betblud code. See D. N. S1atkin and J. S. Robertson, "Extracorporeal Irradiation of Blood by Beta-Emitting Isotopes: Principles of Dose Calculations," Radiat. Res., vo1. 44, pp. $846-54,1970$.
4. W. G. Monahan, R. S. Tilbury and J. S. Laughlin, "Up-take of $13_{N-}$ Labeled Ammonia," J. Nucl. Med. , vol, 13, no. 4, pp. 274-277, 1972 .

5. F. Joliot and I. Curie, "Artificial Production of a New Kind of Radio-Element," Nature, vol. 133, p. 201,1934 .

\section{PUBLICATIONS AND PRESENTATIONS}

Presentations

Griffin, B. I, and F. T. Cross, "An Extracorporeal B1ood Irradiator Source Study," 18th Annual Meeting of the Health Physics Society, Miami, FL, June 17-21, 1973 .
Hungate, F. P., B. I. Griffin, F. T. Cross and W. F. Riemath, "Improvements in Design of a $90 \mathrm{Sr}-90 \mathrm{Y}$ Portable Blood Irradiator," 26th Annual Conference on Engineering in Medicine and Biology, Minneapolis, MN, September 30 to October 4, 1973. 